Portland State University

PDXScholar

$5-5-1995$

\title{
Comparison of Prescribed Versus Actual Gain for Children with Profound Hearing Impairments
}

Kristin Rashelle Gilmer

Portland State University

Follow this and additional works at: https://pdxscholar.library.pdx.edu/open_access_etds

Part of the Speech and Rhetorical Studies Commons

Let us know how access to this document benefits you.

\section{Recommended Citation}

Gilmer, Kristin Rashelle, "Comparison of Prescribed Versus Actual Gain for Children with Profound Hearing Impairments" (1995). Dissertations and Theses. Paper 4975.

https://doi.org/10.15760/etd.6851

This Thesis is brought to you for free and open access. It has been accepted for inclusion in Dissertations and Theses by an authorized administrator of PDXScholar. Please contact us if we can make this document more accessible: pdxscholar@pdx.edu. 


\section{THESIS APPROVAL}

The abstract and thesis of Kristin Rashelle Gilmer for the Master of Science in Speech Communication: Speech and Hearing Science were presented May 5, 1995 and accepted by the thesis committee and the department.

COMMITTEE APPROVALS:
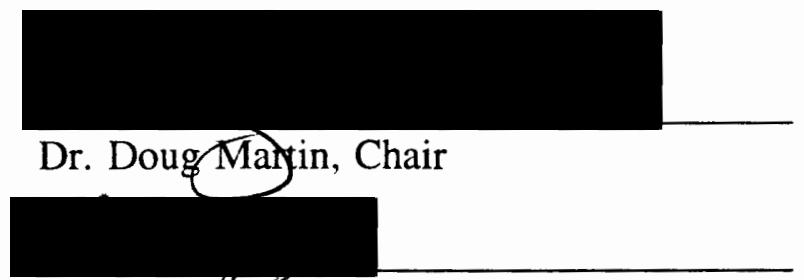

Dr. Don Plapinger

DEPARTMENT APPROVAL

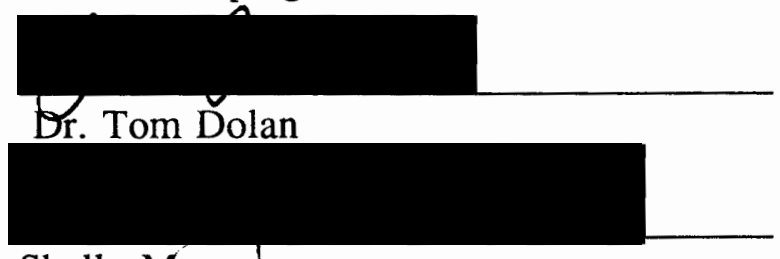

Shelly Maron

Representative of the Office of Graduate Studies

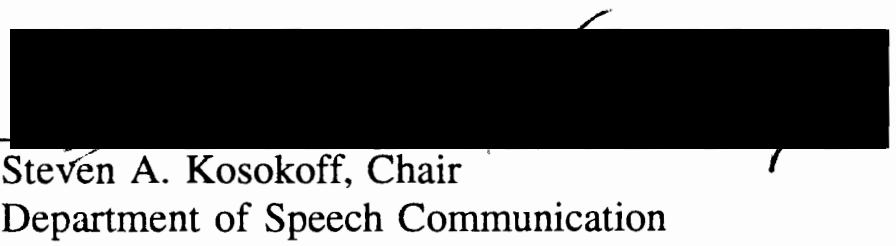

$* * * * * * * * * * * * * * * * * * * * * * * * * * * * * * * * * * * * * * * * * * * * * * * * * * * * * * * * * * * * *$

\section{ACCEPTED FOR PORTLAND STATE UNIVERSITY LIBRARY}

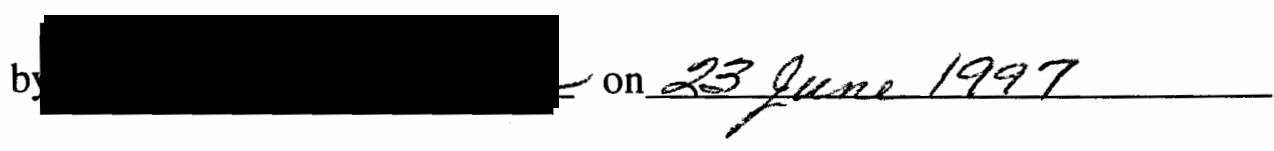




\section{ABSTRACT}

An abstract of the thesis of Kristin Rashelle Gilmer for the Master of Science in

Speech Communication: Speech and Hearing Science presented May 19, 1995.

Title: Comparison of Prescribed Versus Actual Gain for Children with Profound Hearing Impairments.

The early selection and use of an appropriate amplification system may be the most important aspect in the aural rehabilitation of children who are hearing impaired. The main goal guiding the selection of hearing aids for children is to maximize their residual hearing through amplification in order to facilitate speech and language development.

Seewald, Ross, and Stelmachowicz (1987) have developed a speech-spectrum based procedure for selecting hearing aid characteristics for children referred to as the Desired Sensation Level Procedure (DSL) approach. This is an objective method which has been developed specifically for use with young pre-verbal children.

The purpose of the present study was to determine how closely the previouslyfitted amplification systems of profoundly hearing-impaired children approximated the amplification targets that would be prescribed for their hearing losses by the DSL method. The data were used to examine the feasibility and appropriateness of the DSL method for prescribing amplification for children with profound hearing impairments.

Twenty amplification systems worn by profoundly hearing-impaired children were 
electroacoustically evaluated to discover how closely they approximated the DSL fitting criteria. Hearing thresholds were obtained for each subject for the frequencies $250,500,1000,2000$, and $4000 \mathrm{~Hz}$ using puretone audiometry. The DSL computer program was used to generate prescribed $2 \mathrm{cc}$. coupler targets at each frequency. The subjects' amplification systems were electroacoustically analyzed to determine the measured $2 \mathrm{cc}$. coupler response.

Means and standard deviations were reported for prescribed and measured gain values at each frequency. Two-tailed t-tests were computed to determine if a difference exists between prescribed and measured gain. The tests were considered significant at the .05 level. A significant difference between the means was found at 2000 and $4000 \mathrm{~Hz}$. Correlation coefficients were calculated at each frequency to determine if a predictable relationship between prescribed and measured gain existed. Correlation coefficients showed weak relationships between the two groups of data. These results showed the difficulty of meeting prescribed amplification targets, particularly in the high frequencies for children with profound hearing impairments. 
COMPARISON OF PRESCRIBED VERSUS ACTUAL GAIN

FOR CHILDREN WITH PROFOUND HEARING IMPAIRMENTS

by

KRISTIN RASHELLE GILMER

A thesis submitted in partial fulfillment of the

requirements for the degree of

\author{
MASTER OF SCIENCE \\ in \\ SPEECH COMMUNICATION: \\ SPEECH AND HEARING SCIENCE
}

Portland State University

1995 
Table of Contents

Page

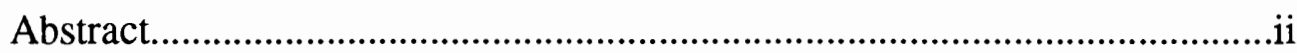

List of Tables.................................................................................... iv

List of Figures............................................................................

Acknowledgements.......................................................................

Chapters

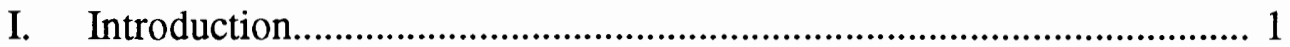

II. Review of the Literature......................................................... 5

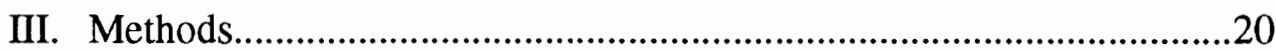

Subjects............................................................................ 20

Procedures........................................................................... 20

Data Analysis...................................................................... 23

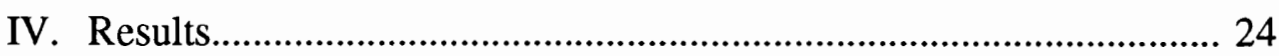

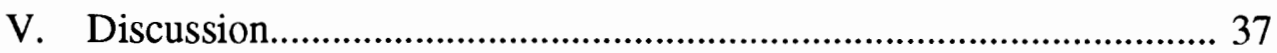

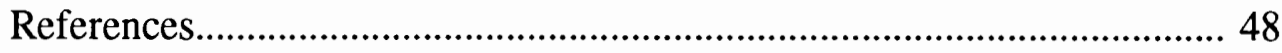




\section{List of Tables}

Table Page

1. Hearing thresholds as a function of test

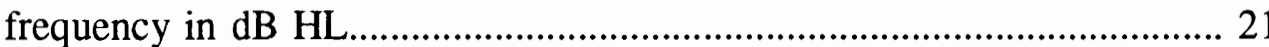

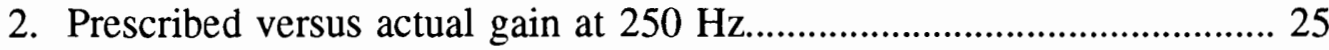

3. Prescribed versus actual gain at $500 \mathrm{~Hz}$............................................ 26

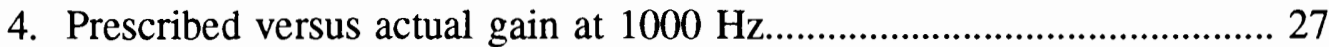

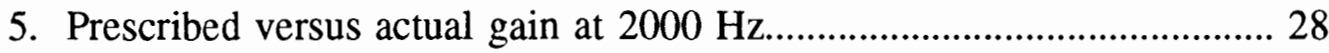

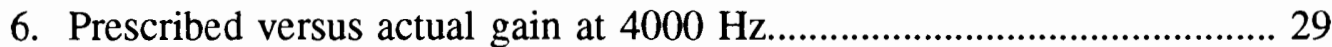

7. Means, standard deviations, and correlation

coefficients for ears with measureable

hearing at all test frequencies. 


\section{List of Figures}

Figure

Page

1. Measured gain as a function of prescribed

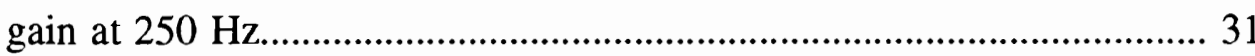

2. Measured gain as a function of prescribed

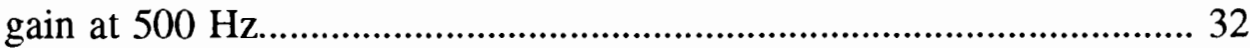

3. Measured gain as a function of prescribed

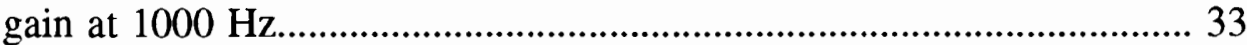

4. Measured gain as a function of prescribed

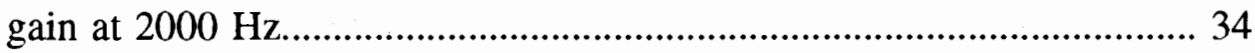

5. Measured gain as a function of prescribed

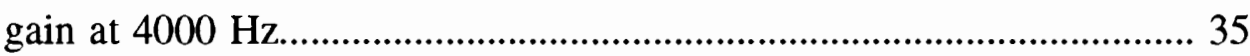

6. Mean differences between measured and

prescribed gain as a function of frequency

36 


\section{ACKNOWLEDGEMENTS}

I wish to thank my thesis advisor, Dr. Doug Martin for his time, support, humor, and computer knowledge. I wish to thank Don Plapinger for providing the opportunity to participate in this study as well as his perceptive comments and suggestions. I would like to also thank my thesis committee members, Dr. Tom Dolan, and Dr. Shelly Maron for their time, input, and support.

I am grateful to the staff and students at Tucker-Maxon Oral School for their valuable support of this project. I wish to especially thank Arilie Adam for allowing me the opportunity to compile the data.

Finally, I wish to thank my husband Ben for his unfailing love, patience and support, not only on this project, but throughout my educational experience. 


\section{Chapter I}

\section{Introduction}

The early selection and use of an appropriate amplification system may be the most important aspect in the aural habilitation of children who are hearing impaired. Hearing loss affects all facets of a child's life, but the primary effect is that it reduces the audibility of the speech signal. In children, hearing loss has been linked to a variety of detrimental effects including speech and language delays, social and emotional problems, and acedemic difficulties (Boothroyd, 1982; Hogson, 1982).

Children appear to have an innate ability to acquire language (Chomsky, 1966; Ling, 1994; Northern \& Downs, 1984). Speech and language skills are the prime facilitators in meeting children's needs and they are learned, by most children, auditorily. In order to learn verbal communication skills children must have sufficient exposure to speech and language, as well as opportunities to relate speech to the people, objects, and events of their lives. For speech and language to be meaningful, it must be used under conditions that allow it to be optimally perceived.

Hearing loss inhibits speech and language acquisition by affecting the audibility and perceived quality of the speech signal. Abnormalities of the auditory system can inhibit the perception of the frequency components, intensity differences, and temporal cues that are crucial in identifying the phonemic differences between speech sounds. Additionally, hearing loss can affect the perception of supra-segmental aspects of speech such as rhythm, intonation, and stress.

The main goal guiding the selection of hearing aids for children is to maximize their residual hearing through amplification in order to facilitate speech and language 
development. Early diagnosis and early use of amplification is critical if children who have hearing losses are to acquire verbal communicative competence. However, as critical as the selection of amplification for children is, it is an area of audiology that can be challenging and problematic.

Many strategies exist which are used successfully to fit adults with hearing aids (Davis \& Mueller, 1987). These methods have been based on the needs of hearingimpaired adults who have an intact speech and language system. Adults can rely on their already developed knowledge of speech and language to compensate for the loss of speech information that is caused by the hearing loss. In contrast, children rely on their hearing to learn speech and language. Consequently, the selection of amplification characteristics that are appropriate for adults may not necessarily be appropriate for children.

Additionally, adults are able to give audiologists feedback regarding the comfort and sound quality of a selected hearing aid system. Audiologists use this information to further modify the electroacoustic characteristics of the selected instrument, resulting in a more appropriate fit. Young children are not able to provide this verbal information.

Finally, audiologists are frequently not able to obtain complete audiological information from a young pre-verbal child prior to the hearing aid fitting. Auditory thresholds that are obtained with behavioral measures are usually less accurate and are often observed, in young children, at intensities above the true threshold (Green, 1988). 
Auditory Brainstem Response (ABR) measurements are often used to predict the hearing sensitivity of infants who are suspected of having hearing loss. This test measures the electrical activity of the lower brain stem in response to sound.

However, the test is limited in that, since click stimuli are typically used to evoke the response, the test is not frequency specific and only reflects responses between the 1000 to $4000 \mathrm{~Hz}$ region (Hall, 1992). Consequently, the selection of a hearing aid must often be based on limited information.

Seewald, Ross, and Stelmachowicz (1987) have developed a speech-spectrum based procedure for selecting hearing aid characteristics for children referred to as the Desired Sensation Level, or DSL, approach. The goal of this method is to select hearing aid frequency and gain characteristics which place the amplified speech signal within the child's most comfortable listening range, enabling audibility of the entire speech spectrum. Based on previous studies, Seewald et al. (1987) have determined the levels, as a function of frequency, to which speech should be amplified, based on the child's hearing thresholds, in order to provide optimal perception of the speech signal.

The DSL method also utilizes a calculation that converts the child's hearing thresholds, which are measured in $\mathrm{dB} \mathrm{HL}$, to $\mathrm{dB}$ SPL. This allows the audiologist to use the same point of reference to compare hearing thresholds, the long term speech spectrum, and the electroacoustic characteristics of hearing aids.

The DSL procedure specifies hearing aid gain in terms of the level to which the long-term speech spectrum should be amplified in order for the child to perceive 
speech. Since this prescription takes into account the signal which is being amplified, the content validity appears to be superior to that of other prescriptive procedures which attempt to predict the most comfortable listening levels based on the threshold of audibility, independent of the effects on the speech spectrum.

The DSL fitting strategy is a systematic approach that has been specifically designed for use with young children. The further development of a method which will effectively prescribe amplification for children by ensuring the audibility of the speech signal may enhance the speech and language development of hearing-impaired children. Although the DSL method may be the most thoroughly developed, and most appropriate method for prescribing frequency and gain targets for children, this procedure has not been clinically tested.

When selecting amplification systems and verifying the appropriateness of hearing aid fittings with children, Seewald et al. (1987) suggest that audiologists try to match the fitting criteria prescribed by the DSL method. But are it's goals achievable for children who have profound hearing impairments? The purpose of this study is to determine how closely the previously-fitted amplification systems worn by children with profound hearing impairments approximate the targets that would be prescribed using the DSL selection method. This data will be used to explore both the feasibility and the appropriateness of the DSL method for prescribing amplification for this population. Twenty amplification systems worn by children with profound hearing impairments will be evaluated to discover how closely they approximate the DSL fitting criteria. 


\section{Chapter II}

Review of the Literature

This review will address the effects of hearing loss on speech perception and speech and language development in children who are hearing impaired, as well as the implications for educational achievement. In addition, current selection strategies for determining amplification characteristics and measures available for determining amplification effectiveness will be discussed.

\section{The Effects of Hearing Loss on Speech Perception}

There has been a general acceptance of the need for early amplification for children who are hearing impaired. Evidence suggests that functional or physiological atrophy of the eighth cranial nerve may result from lack of early auditory stimulation. Northern and Downs (1984) and Ross and Seewald (1988) provided reviews of studies of auditory deprivation in animals. The results of the studies found incomplete maturation of brainstem auditory neurons (Webster \& Webster, 1977, 1979), pathological changes in the brainstem (Evans, Webster, \& Cullen, 1983), inability to resolve differences in sound patterns (Tess, 1967), and an increase in latency of the auditory neural response and abnormal binaural interaction (Clopton \& Silverman, 1977; Silverman \& Clopton, 1977). It is generally believed that for pre-verbal children, the longer the delay in the fitting of appropriate amplification, the lower their auditory potential will be (Ross \& Seewald, 1988).

Speech is made up of time, intensity, and frequency cues. It is necessary to be able to detect the acoustic cues in speech if one is to perceive phonemic distinctions, 
differences in intonation, and rhythm patterns inherent in the speech signal (Fry, 1978). Hearing loss can affect the perception of the speech signal by not only decreasing the perceived loudness of the signal, but also by affecting the perceived quality of the signal. The distortion in sound quality may be caused by interference with the psychoacoustic abilities such as frequency and temporal resolution, and the perception of the time/intensity envelope of speech (Humes, 1982).

Sensorineural hearing impairments may reduce an individuals ability to detect the time onset and offset of sounds, to separate the frequency components of complex sounds, and to integrate changes in intensity over time (Skinner, 1988). Sensorineural hearing losses always involve a loss of discrimination capacity for frequency, and the greater the loss in hearing sensitivity, the poorer the frequency discrimination (Boothroyd, 1982). The effects may cause distortions of the speech signal.

Children who have sensorineural hearing losses also commonly have a reduced dynamic intensity range due to the phenomenon of recruitment. Recruitment refers to the abnormal growth in loudness that is often seen in individuals who have sensorineural hearing losses (Skinner, 1988). Erber (1973) found that the dynamic range for children with severe sensorineural hearing losses may be as low as 10 to 30 dB.

\section{The Effects of Hearing Loss on Speech and Language Development}

The capacity for learning speech and language is at it's peak during the first three years of life. James (1990) suggests that the mechanics of language use are completely mastered during the period of language acquisition, from birth to five 
years. This is the underlying concept for the theory of critical periods which states that there is an optimal time period, during the first years of a child's life, for developing speech and language skills and that once this stage has passed it will become increasingly difficult for a child to acquire verbal communication skills (Bader, 1982; Chomsky, 1966).

An infant with normal hearing can discriminate his mother's voice at birth (DeCasper \& Fifer, 1980). Infants are able to discriminate acoustic differences among speech sounds (James, 1990). At two months of age, infants attend to vocal behavior and begin using non verbal behaviors. At six to eight months of age, infants begin babbling, the beginning of self-reinforcement in language. This is the stage of development where the behavior and development of children who have hearing impairments first deviates from that of children who have normal hearing.

Fry (1978) suggests that babbling is a prerequisite for developing speech skills. It establishes circuits in the brain that connect auditory feedback with kinesthetic feedback. He states that "The high degree of muscular coordination that we exercise when speaking are possible because we both hear and feel ourselves speak" (p. 33). Children who are profoundly hearing impaired babble, but after a time the activity decreases and then ceases altogether. This occurs before the connection between auditory and kinesthetic feedback has been established (Fry, 1978).

There is a general consensus that the greater the residual hearing, the greater the likelihood that the child's speech will be intelligible. There appears to be a relationship between the amount of hearing loss and speech intelligibility. Generally, 
the more profound the hearing loss, the less intelligible the child's speech is likely to be. Children who have hearing impairments often experience problems with speech intelligibility, respiration, phonation, and rate. Studies have found that the percentage of words intelligible to listeners unfamiliar with hearing-impaired speech was less than 25\% (Smith, 1975). Elfenbein, Hardin-Jones, and Davis (1994) found that the speech of children with mild to severe hearing losses was characterized by errors in phoneme substitution, misarticulation of affricates and fricatives, and mild resonance problems.

Much of a hearing-impaired child's errors in speech production are consistent with the reduction in speech information that is caused by the hearing loss ( Elfenbein et al., 1994; Ling, 1994). Insufficient hearing sensitivity around $300 \mathrm{~Hz}$ reduces the audibility of the nasal sounds, $/ \mathrm{m} /, / \mathrm{n} /$, and $/ \mathrm{n} /$, and can interfere with the perception of the rhythm and prosody of speech. High frequency hearing losses may interfere with the perception of unvoiced fricatives, /s/, /O/, and / / (Ling, 1994).

Language is also commonly delayed in children who have hearing losses. During the first years of life, infants develop a bond with their parents who reinforce social, motor, and vocal responses to auditory events. Children begin to associate sound with meaning as parents attach communicative intent to events and objects. With repeated exposure, the child attaches verbal symbols to objects and experiences. Ling (1989) found that children can acquire much of their spoken language skills naturally and spontaneously if their residual hearing is maximized through the use of appropriate amplification.

Studies have found that the acquisition of syntactic rules was delayed in hearing- 
impaired children (Elfenbein et al., 1994; Engen \& Engen, 1983), that they have difficulty with tense markers, possessives, and noun-verb agreements (Elfenbein et al., 1994; Ling, 1994), and exhibit delays in semantic development (Easterbrooks, 1987).

Language delays may also have a perceptual basis that is related to the hearing loss itself. Loss of hearing sensitivity in the low frequencies can interfere with the perception of unstressed syllables, while hearing losses in the high frequencies may affect the perception of voiceless phonemes, such as /s/ and / $/$ / which serve as morphological and verb tense markers (Ling, 1994). The children who participated in the Elfenbein et al. (1994) study reported being self-conscious about their speech and language skills and about the reactions of their peers to the verbal communication errors that they made.

In school, children with hearing impairments may experience acedemic problems related to their hearing loss. A child's language system is the basis for reading ability (Fry, 1978). Reading involves the process of pairing visual shapes with auditory sounds that make up words which convey meaning. Reading is more of an auditory skill than a visual skill, and it is a very important skill for children to acquire if they are to experience educational success. Paul and Jackson (1993) looked at the interrelationship between educational achievement, language, and literacy. They found an inverse relationship between school achievement and amount of hearing loss, which increased with age. They also reported that for children with severe to profound hearing losses, overall educational achievement in all areas was 6 to 7 years lower than their normally hearing peers. 
Additional studies have found that speech skills, reading ability, and proper use of English are strongly associated with educational success (Jenseema \& Trybus, 1978; Hanson, Liberman, \& Schankweiler, 1984; cited in Ling, 1982). Individuals who are hearing impaired, but can communicate using spoken language face fewer social, educational, and vocational restrictions (Ling, 1982).

\section{Hearing Aid Selection Strategies}

There are a variety of procedures available for selecting hearing aids for an individual. Two of the more widely used procedures are the comparison method and the prescription method. The comparison method was first described in the 1940's by Carhart (Millin, 1988a). With this procedure, speech audiometric test results were obtained for the client using a few different hearing aids that had been previously selected. Speech discrimination test results for the different hearing aids were compared, and the one that provided the best scores was ultimately recommended. This procedure was largely abandoned in the 1980's due to the lack of published research substantiating it's reliability or validity, the development and use of custom in-the-ear hearing instruments, and the increasing development and professional acceptance of prescriptive procedures (Millin, 1988a).

Prescriptive procedures utilize a formula to determine the optimal frequency and gain characteristics based on audiological information such as hearing thresholds, most comfortable listening level, and loudness discomfort level. The audiologist evaluates different hearing aids, electroacoustically, to determine the one that comes closest to the prescribed electroacoustic characteristics, for a particular hearing loss (McCandles 
\& Lyregaard, 1983).

Most prescriptive methods, such as the National Acoustics Laboratory- Revised method (NAL-R), (Byrne \& Dillon, 1986), Prescription of Gain/Output of Hearing Aids (POGO), (McCandless \& Lyregaard, 1983); the Berger et al. procedure, (Berger, Hagberg, \& Rane, 1984); and the Libby (1985) procedure, are threshold-based procedures which attempt to predict a listener's preferred listening level from pure-tone threshold information. Most threshold-based prescriptive procedures are derived from, or are modifications of, the half-gain rule. The half-gain rule was first described by Lybarger in 1938 and is based on research which suggests that the preferred listening level of adult hearing aid wearers is approximately equal to one-half of their threshold at each frequency tested (Skinner, 1988).

While several studies have confirmed the validity of this premise, a study by Byrne and Dillon (1986) indicated that when half-gain rules are used with the severely hearing-impaired, much of the speech spectrum remains inaudible. While hearingimpaired adults who have an intact speech and language system can function with some reduction in audibility of the speech spectrum, children cannot. For children with hearing impairments who are learning language, it is crucial that they receive all of the acoustic information in the speech signal if they are to achieve linguistic competence.

Other procedures base their prescriptive formulas on a listeners most comfortable loudness range. These procedures include the Pascoe procedure (Pascoe, 1978; Skinner, Pascoe, Miller, \& Popelka, 1982) and the Cox (1983) procedure. An 
individual's threshold of audibility as well as his preferred listening levels are taken into account. These procedures require sound comfortability and loudness judgements that young children cannot make and are therefore inappropriate for use with this population.

Some prescriptive approaches, such as POGO, the NAL-R, and the Pascoe et al. procedure have modified the half-gain rule based on what is known about the speech spectrum. Most of the energy of speech is concentrated around $500 \mathrm{~Hz}$, with very little energy in the high frequencies (Cox \& Moore, 1988; Green, 1988). Danaher, Osberger, and Pickett (1973) studied the masking effect that vowels, which contain primarily low frequency energy, have on the perception of consonants. They found that speech discrimination was reduced when subjects listened to high level vowel stimuli due to the upward spread of masking. The implication for hearing aid prescription is that over-amplification of the low frequencies can interfere with the perception of higher frequency consonants.

It is also probable that prescriptive approaches that are based on the needs of adults will not provide sufficient overall gain for children with severe to profound hearing losses, especially in the high frequencies (Matkin, 1984). Morris (1977) found that profoundly hearing-impaired children required more gain than adults who had the same amount of hearing loss.

The Desired Sensation Level Procedure

Threshold-based procedures prescribe gain as a proportion of hearing loss. Seewald, Ross, and Spiro (1985) first proposed a procedure, the Desired Sensation 
Level (DSL), for selecting amplification characteristics for children based on the audibility of the speech spectrum. The DSL method uses the speech spectrum as the basis for hearing aid selection. Seewald et al. (1985) proposed that selection methods involving aided detection thresholds did not relate performance to expected speech input levels. The DSL method was designed to calculate the level to which speech must be amplified in order to achieve the desired sensation levels for speech above a given threshold.

The configuration and overall level of the speech spectrum that is chosen to represent conversational speech differs between prescriptive approaches. The speech spectrum is based on the average levels of speech recorded from several speakers at a certain distance, usually one meter. Studies have found that infants are often much closer to the sound source. Turner and Holte (1983) and Stelmachowicz, Mace, Kopun, and Carney (1993) have shown that the speech spectrum varies as a function of distance from the speaker. They found that at a $20 \mathrm{~cm}$ distance from the sound source, the input to a child's hearing aid microphone may be increased by as much as $20 \mathrm{~dB}$. The DSL method utilizes the speech spectrum data that was obtained by Cox (1983) which reflects the more realistic voice levels of a close proximity to the sound source.

An accurate and consistent representation of the speech signal is critical for children who are learning speech and language skills. Deviations from the actual long term speech spectrum and input levels can result in saturation of the hearing aid and distortion of the signal. Additionally, auditory self-monitoring plays a crucial role in 
the speech and language development of children. Studies have shown that the level of our own voice at our ears is approximately $80 \mathrm{~dB}$ SPL (Matkin, 1987); a level which commonly sets hearing aids into saturation and may consequently distort the speech signal.

Based on a study by Erber and Witt (1977), Seewald et al. (1987) concluded that regardless of the degree of hearing loss, the speech signal could be delivered at levels sufficiently above a child's threshold within all the frequency regions where residual hearing is present, including the high frequency regions of $4000 \mathrm{~Hz}$ and above. Research has shown that much of the energy of voiceless phonemes such as /s/, /f/, /O/, and /t/ fall above $4000 \mathrm{~Hz}$ (Levitt, 1978). Morphological markers such as /s/ and /t/ are also primarily high frequency, low intensity phonemes (Levitt, 1978).

The DSL method reduces the amount of amplification in frequency regions below $1000 \mathrm{~Hz}$ (Seewald et al., 1987), especially if the child demonstrates usable residual hearing in the low frequencies, to avoid the upward spread of masking.

Seewald and his colleagues have developed a computer program which allows the audiologist to convert the child's hearing thresholds, measured in hearing level ( $\mathrm{dB}$ HL) into sound pressure level (dB SPL). Residual hearing thresholds, dynamic range, the speech spectrum, sensation levels, and electroacoustic characteristics of hearing aids may then be directly compared. As a result, conversions from soundfield to earphones, and couplers to real ears are automatically calculated.

The DSL method is divided into three main steps. The first step is to quantify the child's threshold of audibility. This step incorporates threshold measures obtained 
through conventional behavioral audiometry as well as any physiological estimates.

The second step is to define the electroacoustical dimensions that will optimize the child's auditory learning. This includes choosing frequency and gain targets and selecting maximum output levels. In order to accomplish this step, Seewald et al. (1987) developed estimates of desired sensation levels (SL's) for amplified speech that varied both as a function of hearing level and frequency region. The desired SL's are added to the child's auditory thresholds to determine the desired levels, within each frequency region, that the speech spectrum should be amplified. The hearing aid and earmold combination that provides gain and output characteristics that are closest to the prescribed target is then selected. Recommendations are also made for adjusting the maximum output, SSPL 90, to define the upper end of the dynamic range. Hawkins, Morrison, Halligan, and Cooper (1989) found that the DSL method prescribed reasonable values for selecting SSPL 90.

The third step is to determine the adequacy of the selection process. Seewald et al. (1987) realized that not all of the audiologic information may be available when selecting amplification systems for young children. In addition, a child's hearing loss can be progressive. Therefore, Seewald and his colleagues advocate re-evaluating the adequacy of the selection periodically. In order to determine the effectiveness of an amplification system, an appropriate method of evaluation must be chosen.

\section{Methods for Determining the Effectiveness of Amplification}

After the audiologist has selected the hearing aid and coupling system which best approximates the prescribed target gain, she must evaluate the extent to which the 
desired characteristics have been achieved.

The conventional way to assess hearing aid performance is to compare the aided hearing thresholds to the unaided hearing thresholds. The difference in these two values is termed functional gain. Schwartz and Larson (1977) pointed out that a disadvantage of this approach is that the aided versus unaided audiogram reflects performance only at threshold, and that there is no assurance that the child will receive meaningful perception of the speech signal at intensities that are above threshold. They also found that this method over-estimated the sensation levels at which average conversational speech would be received by the child.

Additionally, Macrae (1982) found that aided thresholds may underestimate functional gain at frequencies below $1000 \mathrm{~Hz}$ when the hearing threshold is better than $30 \mathrm{~dB}$.

Another traditional approach is to compare aided and unaided word recognition scores. Hawkins, Montgomery, Prosek, and Walden (1987) found the test-retest reliability of this assessment tool to be considerable. Additionally, the face validity of this measure has been questioned since the test items are monosyllabic words which are usually presented in a quiet environment. This is not reflective of the way that people communicate. Furthermore, this method cannot be used with very young or pre-verbal children.

Another procedure which may be used to assess hearing aid performance is through electroacoustical analysis. With this method, the electroacoustic characteristics of the hearing aid are measured in a $2 \mathrm{cc}$. coupler and correction factors 
are applied in order to account for the real-ear-to-coupler difference, which is the difference in SPL developed in a 2 cc. coupler versus the SPL developed in the patient's ear canal. These differences in SPL are due to the differences in acoustic impedance and volume between the human ear and the coupler, the diffraction effects of the head and body, differences in microphone location, and the resonance characteristics of the ear. Measurements obtained in $2 \mathrm{cc}$. couplers tend to underestimate gain relative to real ear measurements, especially in children.

While this method is easy to use and doesn't require subject participation, it's use with children has been contraindicated. The correction factors that are applied to the coupler measurements rely on averaged data of ear canal volume estimates, and therefore may not be representative of the ear canal of an individual child (Seewald, 1988). The acoustics of real ears vary considerably across individuals (Fikret-Pasa \& Revit, 1992). Jirsa and Norris (1978) found that $2 \mathrm{cc}$. couplers underestimated the real ear gain in children by approximately $10 \mathrm{~dB}$.

The DSL approach advocates using real-ear measurements to validate the success of hearing aid fittings for children (Seewald et al., 1987). The probe-tube microphone system is designed to measure the amount of hearing aid amplification at the child's eardrum. This procedure allows the natural ear canal resonating characteristics of the perspective hearing aid wearer to be included in the measurement and includes the effects of the earmold and tubing and the head and body diffraction effects. It is also a faster measure to obtain than behavioral aided assessment, and does not require active cooperation from the child. 
The DSL procedure utilizes an in-situ measurement to determine hearing aid adequacy. Cox and Alexander (1990) found that for prescriptions like the DSL, which specify frequency and gain characteristics in terms of the desired level of amplified speech, insertion gain measures did not verify the appropriateness of the hearing aid fitting. Insertion gain measures refer to the difference in dB SPL between the aided real-ear response and the unaided real-ear response. In-situ gain, however, is the realear response in reference to a certain input, for example $70 \mathrm{~dB}$ SPL. They found that in-situ measures were a more direct measurement of speech amplification in the ear canal because they portray hearing aid performance under conditions that resemble it's actual use. By measuring the real-ear aided response, the clinician can directly compare the performance of the hearing aid, the relationship between hearing thresholds and the speech spectrum, and the output limiting characteristics of the hearing aid (Seewald et al., 1987).

Using signal levels that approximate the long term speech spectrum, the SPL output of the hearing aid at the level of the eardrum is measured using a probe-tube microphone system. The measured SPL output is compared with the SPL of the input signal to determine the in-situ gain as a function of frequency. This measurement provides an estimate of the amplified average speech spectrum (Seewald, Hudson, Gagne, and Zelisko, 1992). At each frequency, the in-situ gain values are added to the long term speech spectrum values.

When real-ear measures cannot be utilized, the DSL program will apply average real-ear-to-coupler correction factors based on the child's age. 


\section{Summary and Conclusions}

Hearing loss affects the audibility of the speech signal and impairs abilities such as temporal and frequency resolution. It thereby affects the quality of the perceived signal (Humes, 1982). Additionally, the effects of the hearing impairment on the speech, language, and acedemic development of young children can be devastating. Appropriate amplification of children's residual hearing is one of the most crucial aspects in their rehabilitation. Because children cannot provide information about the appropriateness of the amplification that they receive, it is imperative that audiologists use the most valid and reliable hearing aid selection methods available. After an amplification system has been selected, continual assessment and monitoring of that system will be required to ensure the most appropriate fit. As more information about the child's hearing loss is obtained, adjustments to the hearing aid will need to be made. 


\section{Chapter III}

\section{Methods}

\section{Subjects}

Sixteen children between the ages of two to eight years were recruited through a private oral/auditory school in Portland, Oregon. The collected data yielded results for 20 ears. Six of the subjects were male and 10 of the subjects were female. All subjects had bilateral profound sensorineural hearing losses, and were fit with amplification systems. Their hearing thresholds, in dB HL (ANSI S3.6, 1989) are displayed in Table 1. Four subjects, 3 males and 1 female, yielded useable bilateral data. Of the remaining 12 subjects, 7 were using cochlear implants and data was obtained only for the non-implanted ear. All 7 of those subjects, which included 5 females and 2 males, were wearing amplification systems in the non-implanted ear. For the remaining 5 subjects, 1 male and 4 females, the ear with the greatest amount of hearing loss was selected as the test ear.

\section{Procedures}

Threshold data was obtained for each subject using behavioral audiometry under TDH-49 headphones in a sound-treated booth. Standard immitance measurements were obtained for each subject prior to testing to rule out middle ear pathology. The subject's thresholds for the frequencies of $250,500,1000,2000$, and $4000 \mathrm{~Hz}$ were entered into the DSL computer program.

A threshold of $130 \mathrm{~dB}$ was entered for subjects who did not exhibit measurable thresholds at the limits of the audiometer. The program will not calculate prescribed gain at frequencies for which there is no response. For the purposes of this study, it 
Table 1

Hearing Thresholds as a Function of Test Frequency in dB HL

Frequency $(\mathrm{Hz})$

\begin{tabular}{crrrrr} 
Subject & 250 & 500 & 1000 & 2000 & 4000 \\
\hline 1 & 90 & 100 & 105 & NR & NR \\
2 & 75 & 90 & 95 & 110 & NP \\
3 & 75 & 95 & 105 & 110 & NR \\
4 & 60 & 25 & 95 & 110 & 90 \\
5 & 80 & 85 & 95 & 100 & 90 \\
6 & 80 & 85 & 95 & 105 & 105 \\
7 & 60 & 95 & 110 & NP & NR \\
8 & 100 & 105 & 120 & 115 & 100 \\
9 & 100 & 120 & 120 & 120 & 90 \\
10 & 60 & 90 & 100 & 105 & 120 \\
11 & 100 & 105 & 110 & 105 & 110 \\
12 & 95 & 90 & 95 & 110 & 120 \\
13 & 75 & 85 & 105 & NR & NR \\
14 & 90 & 120 & $N R$ & NP & NP \\
15 & 65 & 110 & 115 & NP & NP \\
16 & 85 & 110 & 120 & NR & NR \\
17 & 6.5 & 90 & 100 & 105 & 105 \\
18 & 100 & 95 & 115 & NR & NR \\
19 & 80 & 100 & 110 & 115 & 110 \\
30 & 65 & 95 & 100 & 105 & 105
\end{tabular}

Note. $N R=$ No response at the limits of the audiometer. 
was decided that $130 \mathrm{~dB} \mathrm{HL}$ would be used to represent the subject's threshold at frequencies for which there was no measurable response.

The DSL selection method was used to calculate the optimal prescribed gain as a function of frequency at $250,500,1000,2000$, and $4000 \mathrm{~Hz}$. Based on the unaided threshold data, this calculation specified frequency/gain targets and their relationship to the desired sensation levels for the long-term average speech spectrum (Seewald et al., 1987). Information about the subject's amplification system, such as type, make, and model of the device, as well as the earmold coupling system, was also entered into the program. The program applied correction factors, based on the subject's age to account for the real-ear-to-coupler difference. The program then generated prescribed 2 cc. coupler gain targets for each subject.

An electroacuostic analysis of each child's amplification system was measured with a Frye 5500 hearing aid analyzer and a 2 cc coupler. The hearing aids were measured at the volume control settings that the subjects were using on the day of testing. The input level was $60 \mathrm{~dB}$.

The SPL level measured in the 2 cc. coupler by the electroacoustic analyzer was recorded as a function of frequency. This measurement was compared against the target 2 cc. coupler gain that was prescribed by the DSL in order to determine if the subject's present hearing aid amplification systems were providing the auditory input that was predicted from the DSL selection method. For the purposes of this study, the possibility of distortion and saturation of the subjects' hearing aid systems was not investigated. 
Data Analysis

The primary question that was posed in this study regards whether the hearing aid fittings of children with profound hearing impairments differ from prescribed optimal fittings according to the DSL selection method. Electroacoustic gain and prescribed gain were compared for each child. An acceptance criterion of $+/-5 \mathrm{~dB}$ was used to determine significant differences (Ross \& Seewald, 1988).

Additionally, a Pearson product moment correlation was used to compare hearing aid amplification as a function frequency for the desired response versus the actual measured response. To determine the significant differences between the means of both groups of data, a repeated measures t-test was used to compare the means computed from the actual versus prescribed coupler gain values at each frequency. 


\section{Chapter IV}

\section{Results}

The difference in $\mathrm{dB}$ SPL between the measured versus the prescribed $2 \mathrm{cc}$. coupler gain was computed for each subject at each frequency. Tables $2,3,4,5$, and 6 display the raw data of subjects that satisfied the $+/-5 \mathrm{~dB}$ criteria level for each frequency, as well as those who received either too little or too much gain according to the DSL prescription. No subject met the prescribed criteria at each frequency.

In the low to middle frequencies of 250 to $1000 \mathrm{~Hz}$ subjects who did not meet the DSL fitting criteria tended to be over-amplified with respect to their prescribed gain targets. At $250 \mathrm{~Hz}, 45 \%$ of the subjects were within the prescribed target criteria, while $30 \%$ were over-amplified and $25 \%$ were under-amplified.

At $500 \mathrm{~Hz}, 35 \%$ of subjects met the criteria for prescribed gain while $45 \%$ received too much amplification and $20 \%$ received insufficient amplification according to their DSL targets.

At $1000 \mathrm{~Hz}, 40 \%$ of the subjects were amplified in accordance with the prescribed gain while $35 \%$ were over- amplified and $25 \%$ were under-amplified.

At the higher frequencies of 2000 and $4000 \mathrm{~Hz}$, none of the subjects' amplification systems provided too much gain according to the DSL prescription. Only $30 \%$ of th subjects met the prescribed criteria at $2000 \mathrm{~Hz}$, while $10 \%$ were within criteria at $4000 \mathrm{~Hz}$. At $2000 \mathrm{~Hz}, 70 \%$ were under-amplified; at $4000 \mathrm{~Hz}, 90 \%$ were underamplified.

Means and standard deviations were computed at each frequency for the prescribed $2 \mathrm{cc}$. coupler responses and the measured $2 \mathrm{cc}$. coupler responses for each 
Table 2

Prescribed Versus Actual Gain at $250 \mathrm{~Hz}$

\begin{tabular}{|c|c|c|c|}
\hline Subject & $P x$ & Actual & Difference \\
\hline 1 & 49 & 46 & .3 \\
\hline 2 & 38 & 52 & 14 \\
\hline 3 & 36 & 40 & $2^{2}$ \\
\hline 4 & 26 . & 45 & 19 \\
\hline 5 & 42 & 50 & 8 \\
\hline 6 & $4 c^{2}$ & 27 & -15 \\
\hline 7 & 42 & 43 & 1 \\
\hline 6 & 55 & 46 & -9 \\
\hline 9 & 55 & 54 & -1 \\
\hline 10 & $4 \hat{\imath}$ & 50 & 8 \\
\hline 11 & 54 & 52 & -2 \\
\hline 12 & 51 & 40 & -11 \\
\hline 13 & 36 & 57 & 21 \\
\hline 14 & 47 & 40 & -7 \\
\hline 15 & 45 & 40 & -5 \\
\hline 16 & 45 & 46 & 3 \\
\hline 17 & 30 & 39 & 9 \\
\hline 16 & 55 & 42 & -13 \\
\hline 19 & 42 & 40 & $\therefore$ \\
\hline 20 & 45 & 44 & -1 \\
\hline Mean & 43.95 & 44.75 & 0.80 \\
\hline St. Dev. & 8.03 & 6.81 & 6.56 \\
\hline$t$ & \multicolumn{2}{|c|}{-0.34} & \\
\hline$p$ & \multicolumn{2}{|c|}{.74} & \\
\hline
\end{tabular}

Note. $P x=$ Prescribed $2 \mathrm{cc}$. coupler gain in $\mathrm{dB}$ SPL.

Actual=Measured $2 \mathrm{cc}$. coupler gain in dB SPL.

Underlined, italicized values indicate under-amplification.

Bold, italicized values indicate over-amplification.

$\mathrm{t}=$ calculated $\mathrm{t}$-value between prescribed and actual means at the .05 level. $\mathrm{p}=$ probability value of $\mathrm{t}$-test at the .05 level. 
Table 3

Prescribed Versus Actual Gain at $500 \mathrm{~Hz}$

\begin{tabular}{|c|c|c|c|}
\hline Subject & $P x$ & Actual & Difference \\
\hline 1 & 51 & 53 & 2 \\
\hline 2 & 45 & 56 & 11 \\
\hline 3 & 48 & 56 & 8 \\
\hline 4 & 41 & 53 & 12 \\
\hline 5 & 41 & 59 & 18 \\
\hline 6 & 41 & 33 & -6 \\
\hline 7 & 48 & $\overline{44}$ & -4 \\
\hline 8 & 54 & 55 & 1 \\
\hline 9 & 61 & 58 & -3 \\
\hline 10 & 45 & 56 & 11 \\
\hline 11 & 50 & 59 & 9 \\
\hline 12 & 41 & 47 & 6 \\
\hline 13 & 37 & 59 & 22 \\
\hline 14 & 57 & 43 & -14 \\
\hline 15 & 53 & 42 & -11 \\
\hline 16 & 57 & $\overline{59}$ & 2 \\
\hline 17 & 45 & 47 & 2 \\
\hline 16 & 45 & 51 & 6 \\
\hline 19 & 51 & 45 & -6 \\
\hline 20 & 48 & 49 & 1 \\
\hline Nean & 47.95 & 51.20 & 3.25 \\
\hline St. Dev. & 6.35 & 7.23 & 9.33 \\
\hline$t$ & \multicolumn{2}{|c|}{-1.51} & \\
\hline$p$ & \multicolumn{2}{|c|}{.14} & \\
\hline
\end{tabular}

Note. Px=Prescribed $2 \mathrm{cc}$. coupler gain in $\mathrm{dB}$ SPL.

Actual=Measured $2 \mathrm{cc}$. coupler gain in dB SPL.

Underlined, italicized values indicate under-amplification.

Bold, italicized values indicate over-amplification.

$\mathrm{t}=$ calculated $\mathrm{t}$-value between prescribed and actual means at the .05 level.

$\mathrm{p}=$ probability value of $\mathrm{t}$-test at the .05 level. 
Table 4

Prescribed Versus Actual Gain at $1000 \mathrm{~Hz}$

\begin{tabular}{|c|c|c|c|}
\hline Subject & $P x$ & Actual & Difference \\
\hline 1 & 59 & 70 & 11 \\
\hline 2 & 54 & 63 & 9 \\
\hline 3 & 59 & 62 & 3 \\
\hline 4 & 54 & 65 & 11 \\
\hline 5 & 54 & 67 & 13 \\
\hline 6 & 54 & 36 & -16 \\
\hline$T$ & 61 & $\overline{42}$ & -19 \\
\hline$a$ & 65 & $\overline{70}$ & 5 \\
\hline 9 & 6.5 & 68 & 3 \\
\hline 10 & $5 T$ & 61 & 4 \\
\hline 11 & 56 & 62 & 6 \\
\hline 12 & 49 & 52 & 3 \\
\hline 13 & 54 & 64 & 10 \\
\hline 14 & 60 & 47 & -13 \\
\hline 15 & 60 & $\underline{46}$ & -14 \\
\hline 16 & 65 & 65 & 0 \\
\hline 17 & 57 & 63 & 6 \\
\hline 18 & 60 & 6.5 & 5 \\
\hline 19 & 61 & $\underline{53}$ & -8 \\
\hline 20 & 57 & $\overline{56}$ & -1 \\
\hline Mean & 58.05 & 58.95 & 0.90 \\
\hline St. Dev. & 4.27 & 9.49 & 9.70 \\
\hline $\mathrm{t}$ & \multicolumn{2}{|c|}{-0.39} & \\
\hline$p$ & \multicolumn{2}{|c|}{.70} & \\
\hline
\end{tabular}

Note. $\mathrm{Px}=$ Prescribed $2 \mathrm{cc}$. coupler gain in $\mathrm{dB}$ SPL.

Actual=Measured 2 cc. coupler gain in dB SPL.

Underlined, italicized values indicate under-amplification.

Bold, italicized values indicate over-amplification.

$\mathrm{t}=$ calculated $\mathrm{t}$-values between prescribed and actual means at the .05 level.

$\mathrm{p}=$ probability value of $\mathrm{t}$-test at the .05 level. 
Table 5

Prescribed Versus Actual Gain at $2000 \mathrm{~Hz}$

\begin{tabular}{|c|c|c|c|}
\hline Subjects & $P x$ & Actual & Difference \\
\hline 1 & 72 & 63 & -9 \\
\hline 2 & 66 & 63 & -3 \\
\hline 3 & 68 & 59 & .9 \\
\hline 4 & 68 & 60 & -8 \\
\hline 5 & 63 & 65 & 2 \\
\hline 6 & 66 & 40 & -26 \\
\hline 7 & 72 & 39 & -33 \\
\hline 8 & 69 & $\overline{63}$ & -6 \\
\hline 9 & 71 & $\overline{61}$ & -10 \\
\hline 10 & 66 & $\overline{63}$ & -4 \\
\hline 11 & 61 & 63 & 2 \\
\hline 12 & 63 & $\underline{55}$ & -8 \\
\hline 13 & 67 & $\overline{63}$ & -4 \\
\hline 14 & 67 & 47 & -20 \\
\hline 15 & 68 & $\overline{46}$ & -22 \\
\hline 16 & 72 & 66 & -6 \\
\hline 17 & 66 & $\overline{61}$ & -5 \\
\hline 18 & 68 & 60 & -8 \\
\hline 19 & 69 & $\overline{56}$ & .13 \\
\hline 20 & 66 & $\underline{60}$ & -6 \\
\hline Mean & 67.50 & 57.65 & -9.85 \\
\hline Std. D. & 3.00 & 8.13 & 8.95 \\
\hline $\mathrm{t}$ & \multicolumn{2}{|c|}{5.09} & \\
\hline$p$ & \multicolumn{2}{|c|}{0.00} & \\
\hline
\end{tabular}

Note. Px=Prescribed $2 \mathrm{cc}$. coupler gain in $\mathrm{dB}$ SPL. Actual $=$ Measured $2 \mathrm{cc}$. coupler gain in $\mathrm{dB}$ SPL.

Underlined, italicized values indicate under-amplification.

Bold, italicized values indicate over-amplification.

$\mathrm{t}=$ calculated $\mathrm{t}$-value between prescribed and actual means at the .05 level. $\mathrm{p}=$ probability values of t-test at the .05 level. 
Table 6

Prescribed Versus Actual Gain at $4000 \mathrm{~Hz}$

\begin{tabular}{|c|c|c|c|}
\hline Subject & $P x$ & Actual & Difference \\
\hline 1 & 76 & 58 & -20 \\
\hline 2 & 78 & $\underline{58}$ & -20 \\
\hline 3 & 76 & 51 & -27 \\
\hline 4 & 59 & $\overline{51}$ & -8 \\
\hline 5 & 59 & $\overline{58}$ & -1 \\
\hline 6 & 66 & 31 & -37 \\
\hline 7 & 78 & $\overline{28}$ & -50 \\
\hline 6 & 6.5 & 59 & -6 \\
\hline 9 & 59 & $\overline{60}$ & 1 \\
\hline 10 & 75 & 60 & -15 \\
\hline 11 & 67 & $\overline{57}$ & -10 \\
\hline 12 & 72 & $\overline{52}$ & -20 \\
\hline 13 & 75 & $\overline{59}$ & -16 \\
\hline 14 & 75 & $\overline{35}$ & -40 \\
\hline 15 & 76 & 40 & -36 \\
\hline 16 & 76 & 29 & -49 \\
\hline 17 & 68 & 59 & -9 \\
\hline 18 & 76 & $\overline{57}$ & -19 \\
\hline 19 & 70 & $\overline{51}$ & -19 \\
\hline 20 & 68 & $\overline{55}$ & -13 \\
\hline Mean & 71.10 & 50.45 & -20.65 \\
\hline St. Dev. & 6.71 & 11.20 & 14.77 \\
\hline$t$ & \multicolumn{2}{|c|}{7.10} & \\
\hline$p$ & \multicolumn{2}{|c|}{0.00} & \\
\hline
\end{tabular}

Note. Px=Prescribed 2 cc. coupler gain in dB SPL.

Actual=Measured $2 \mathrm{cc}$. coupler gain in dB SPL.

Underlined, italicized values indicate under-amplification.

Bold, italicized values indicate over-amplification.

$\mathrm{t}=\mathrm{calculated} \mathrm{t}$-value between prescribed and actual means at the .05 level.

$\mathrm{p}=$ probability value of $\mathrm{t}$-test at the .05 level. 
subject. The data are presented in Tables 2 through 6 . Additionally, the mean differences between these data were examined using repeated measures t-tests at each frequency. As seen in Table 5 and 6, the t-test results indicated significant differences at the between the means, at the .05 level, at 2000 and $4000 \mathrm{~Hz}$. Probability values were insignificant at 250,500 , and $1000 \mathrm{~Hz}$, but were significant at 2000 and 4000 $\mathrm{Hz}$.

While Tables 2 through 6 reveal significant differences between the mean measured coupler gain versus prescribed gain at 2000 and $4000 \mathrm{~Hz}$, it was deemed important to examine the relationship between prescribed versus measured gain for the individual subjects. Therefore, Pearson product moment correlations were computed at each frequency. Figures 1 through 5 display scatterplot diagrams of measured versus prescribed gain at each frequency. The correlation coefficients are reported in Figures 1 through 5 . These figures and correlation coefficients suggest very weak relationships between the prescribed and measured gain at each test frequency.

The mean differences between prescribed gain and measured gain as a function of frequency are displayed in Figure 6. 
Figure 1

Measured Gain as a Function of Prescribed Gain at $250 \mathrm{~Hz}$

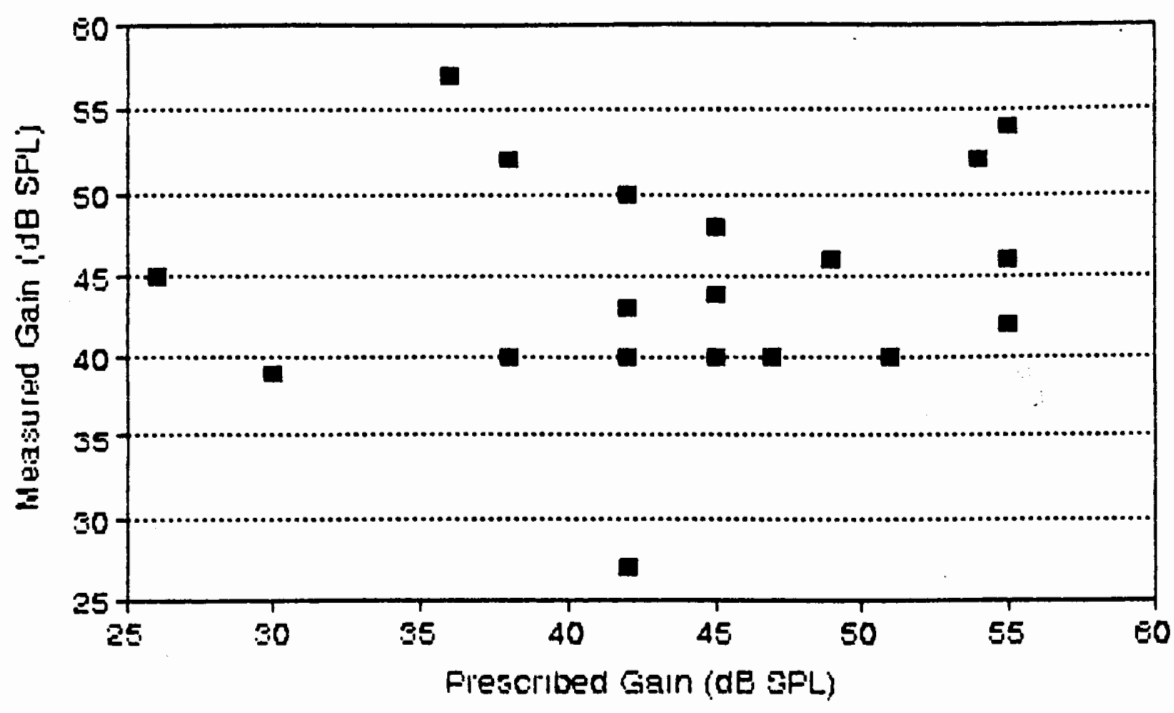

- Measured Gain $r=0.10$ 
Figure 2

Measured Gain as a Function of Prescribed Gain at $500 \mathrm{~Hz}$

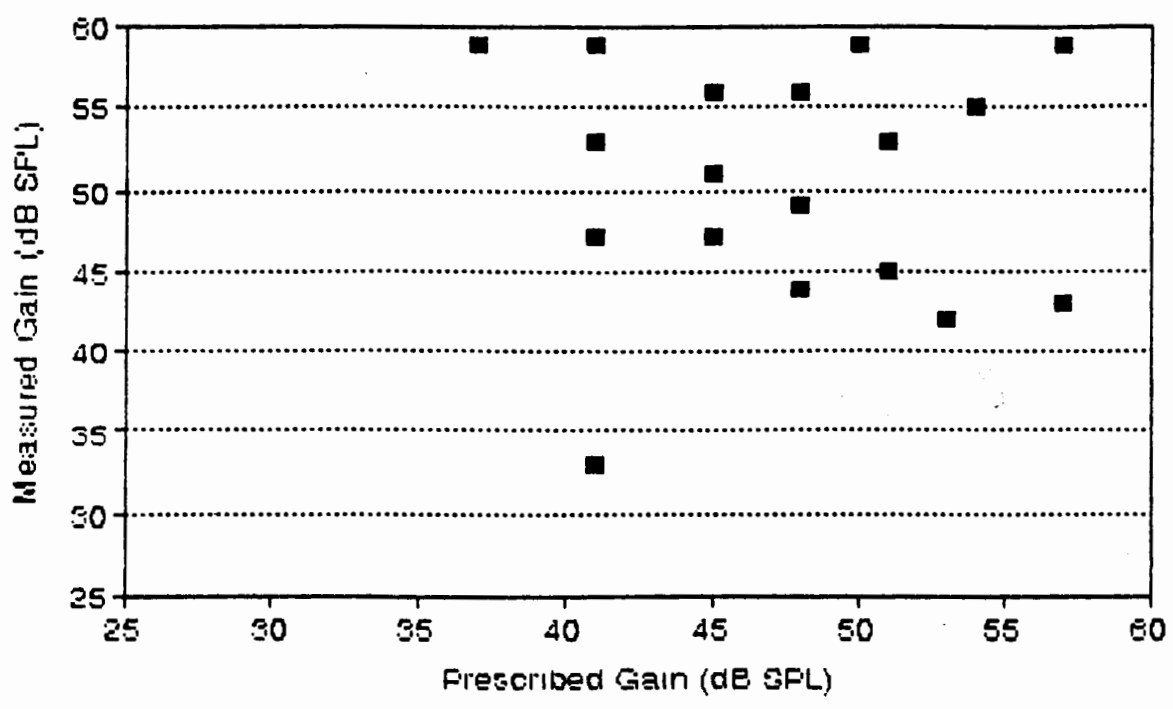

Measured Gian $\quad r=0.00$ 
Figure 3

Measured Gain as a Function of Prescribed Gain at $1000 \mathrm{~Hz}$

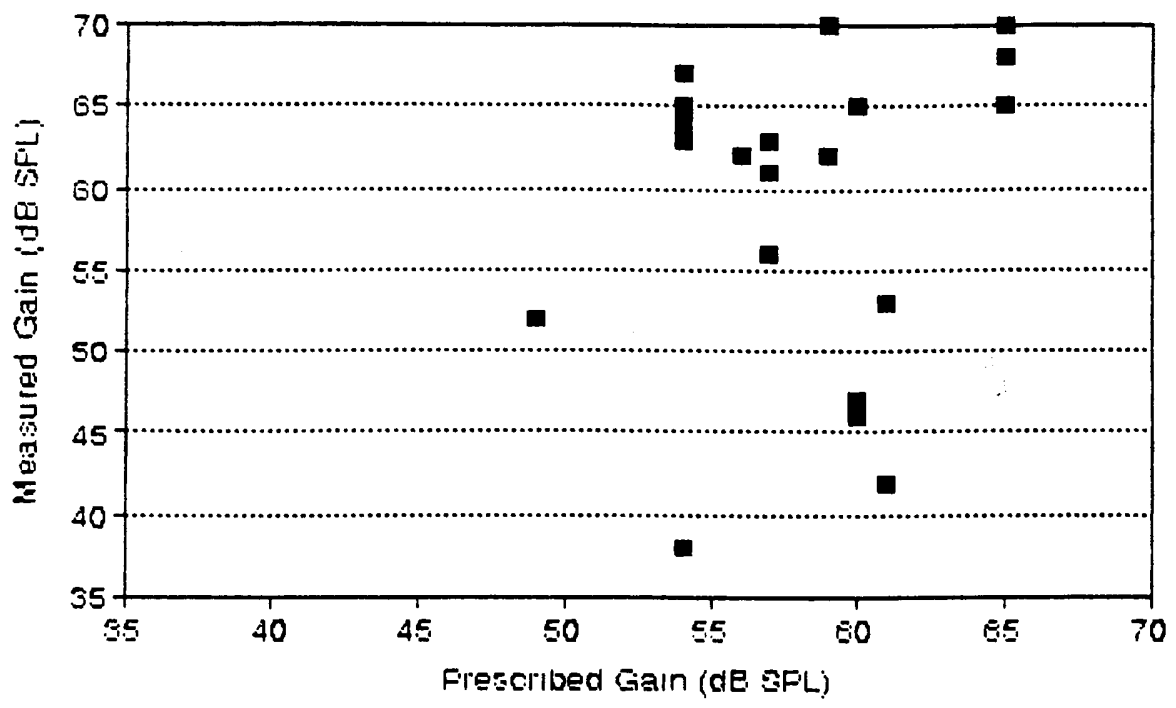

- Measured Gain $r=0.1 \Xi$ 
Figure 4

Measured Gain as a Function of Prescribed Gain at $2000 \mathrm{~Hz}$

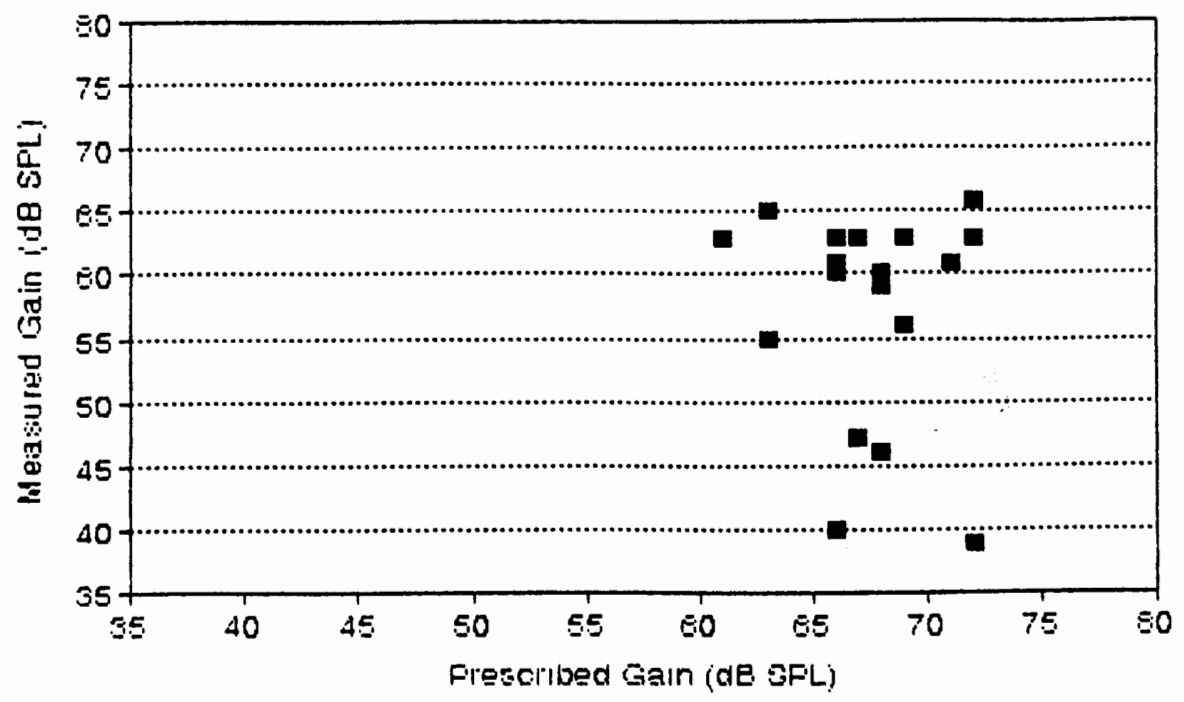

- Measured Gain $\quad r=-0.10$ 
Figure 5

Measured Gain as a Function of Prescribed Gain at $4000 \mathrm{~Hz}$

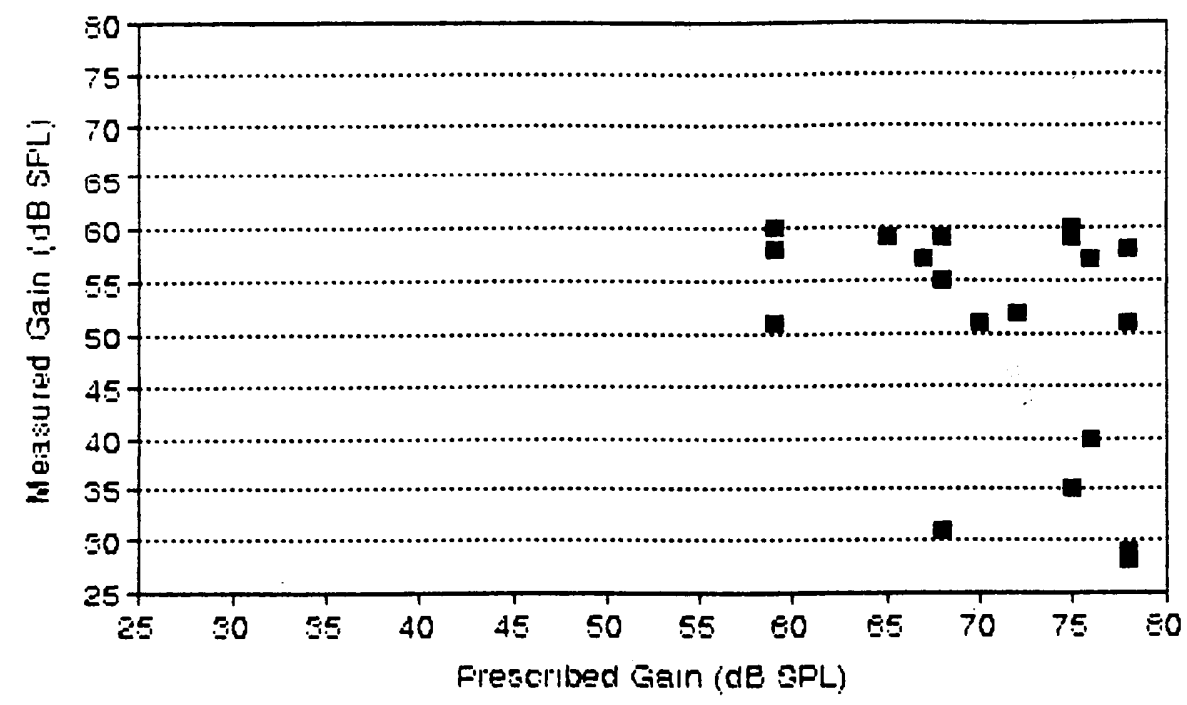

- Measured Gain $r=-0.33$ 
Figure 6

Mean Differences Between Measured and Prescribed Gain as a Function of Frequency

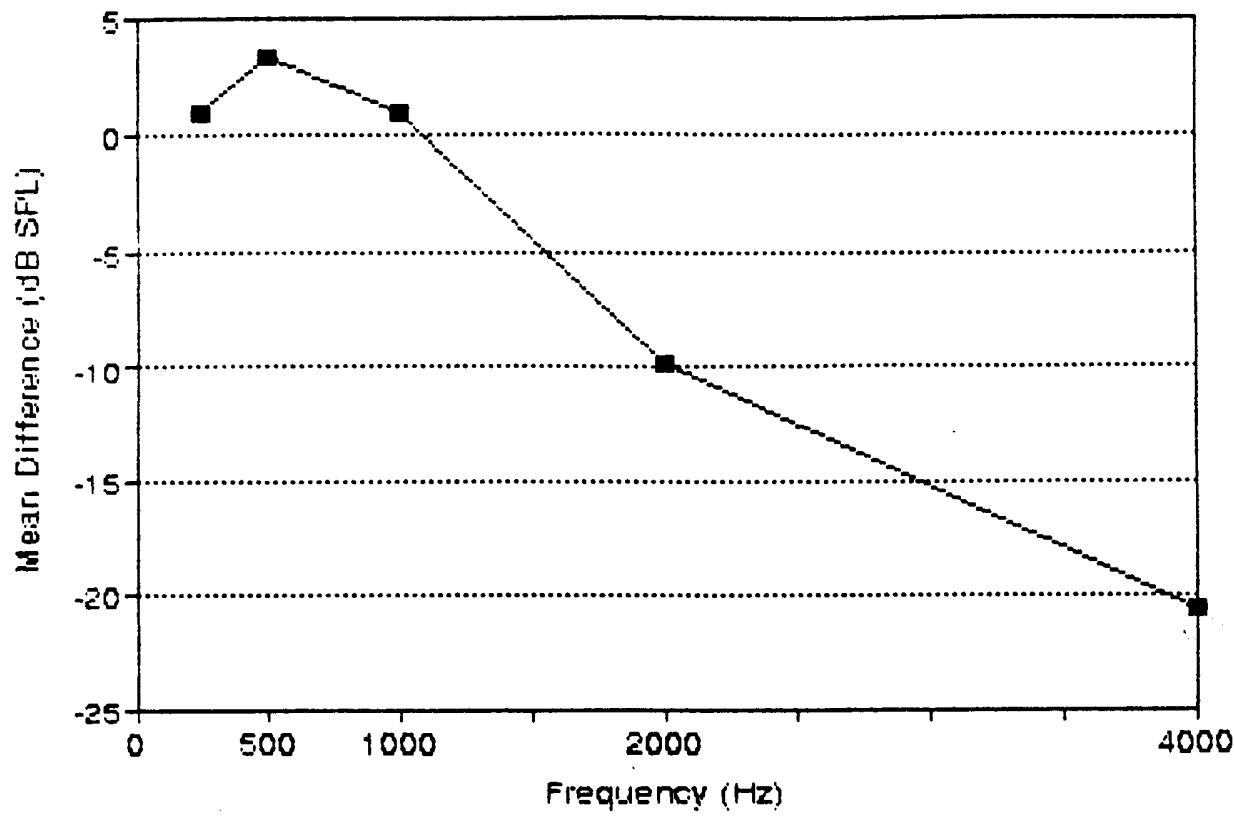




\section{Chapter V}

Discussion

The purpose of this study was to examine whether the ideal amplification prescribed by the DSL could be realized with children who have profound sensorineural hearing impairments. The gain received through the previously-fitted hearing aid systems of sixteen children was compared with the gain that would be prescribed for their hearing losses using the DSL selection method. Appropriate amplification of a hearing-impaired child's residual hearing is crucial if he is to develop speech and language skills. Additionally, many of a hearing-impaired child's speech production errors are consistent with the reduction in speech information caused by their hearing loss (Elfenbein et al., 1994; Ling, 1994).

The DSL prescription method is unique in that it has been designed and developed specifically for children. The goal of the DSL is to make all of the sounds of speech audible to the child. The premise is that by achieving the amplification levels as a function of frequency prescribed by the DSL, the audiologist will ensure the audibility of the entire speech spectrum.

Twenty amplification systems worn by sixteen children with profound hearing impairments were analyzed and compared to see how closely they approximated the DSL prescribed characteristics. The data were examined as a function of frequency to determine if a predictable relationship between prescribed versus measured gain existed. The majority of subjects failed to satisfy the prescribed gain criteria, particularly at the higher frequencies of 2000 and $4000 \mathrm{~Hz}$.

These results have several implications. First, $30 \%$ of the subjects were over- 
amplified at $250 \mathrm{~Hz}$, while $45 \%$ were over-amplified at $500 \mathrm{~Hz}$. Over-amplification of the low frequencies can lead to an upward spread of masking which can interfere with the perception of higher frequency second formant transitions (Danaher, Wilson, \& Pickett, 1978). Second formant transitions are important cues in the perception of high frequency consonants (Seewald \& Ross, 1988) and the masking of these cues by over-amplified low frequency speech energy can result in difficulties with speech perception.

A second implication concerns the under-amplification of the high frequencies. Seventy percent and $90 \%$ of the subjects received insufficient amplification at 2000 and $4000 \mathrm{~Hz}$, respectively. Inadequate amplification of the higher frequencies can affect perception of the voiceless fricative and stop phonemes in which much of the energy falls above $2000 \mathrm{~Hz}$, such as $/ \mathrm{s} /, / /, / \mathrm{t} /, / \mathrm{c} /, / 0 /$, and $/ \mathrm{f} /$. The phonemes $/ \mathrm{t} /$ and /s/ also serve as critical morphological markers, important in language perception and production.

A question arises then, as to why the subjects were not receiving optimal amplification according to the DSL prescription method. There are several possibilities. One argument may be that the children that participated in this study were fit inappropriately. The subjects that participated in this study were students at a private auditory/oral school. The school employs a full-time audiologist who regularly monitors and evaluates the student's hearing loss and their hearing aid fittings, providing any necessary adjustments and repairs. The children's amplification systems are electroacoustically tested on a weekly basis to determine if they are providing the 
required amount of amplification. While this system does not ensure quality hearing aid fittings, it is difficult to conceive of a situation in which students with profound hearing impairments could receive better audiologic care.

Another argument is that current hearing aid technology is not compatible with providing the amount of high frequency amplification that is required to meet the DSL prescribed levels for children who are profoundly hearing-impaired. At $4000 \mathrm{~Hz}$, the mean amount of gain prescribed for the subjects was $71 \mathrm{~dB}$ SPL. Commercially available hearing aids do not provide this amount of amplification at the higher frequencies. It is theoretically possible, considering current hearing aid technology, that sufficient high frequency amplification could be provided which would allow the audiologist to achieve prescribed DSL targets in the high frequencies for children with profound hearing impairments. However, manufacturing practices reduce the high frequency output of the amplifier in order to minimize acoustic feedback (Millin, 1988b).

Mueller (1990) noted that in clinical situations, measured gain is typically insufficient by $17 \mathrm{~dB}$ or more at $4000 \mathrm{~Hz}$ when compared with prescribed gain. In the present study, measured gain at $4000 \mathrm{~Hz}$ was insufficient by an average of $21 \mathrm{~dB} \mathrm{SPL}$ when compared to prescribed gain. Mueller suggests that a large deviation from the prescribed target value must be accepted at frequencies above $4000 \mathrm{~Hz}$ (cited in Dempsey, 1994).

Based on a study by Lundh (1982), Drylund and Lundh (1990) determined the maximum insertion gain that could be achieved before the occurrence of feedback for 
the ears and earmolds of children fitted with power BTE hearing aids. The average amount of gain that could be provided by the hearing aid before feedback would occur was approximately $61 \mathrm{~dB}$ SPL at $2000 \mathrm{~Hz}$, and $43 \mathrm{~dB}$ SPL at $4000 \mathrm{~Hz}$. The authors of the study further determined that prescribed gain requirements could not be satisfied at frequencies for which the child's hearing loss was greater than $100 \mathrm{~dB} \mathrm{HL}$.

A question arises then, as to the appropriateness of DSL targets for children with profound hearing losses. Nine of the subjects in this study did not have measurable hearing across all of the frequencies tested. A subset of the data was analyzed on the subjects who had measurable hearing at 250 through $4000 \mathrm{~Hz}$. The results of this analysis are displayed in Table 7.

As a group, these subjects also tended to receive under-amplification in the 2000 and $4000 \mathrm{~Hz}$ region when compared with their prescribed DSL targets. Only two subjects with measurable hearing at all test frequencies achieved the prescribed gain values at $4000 \mathrm{~Hz}$. Both children who met the prescribed criteria at that frequency had hearing thresholds of $90 \mathrm{~dB} \mathrm{HL}$, which appears to agree with the findings of Drylund and Lundh (1990). When subjects failed to meet prescribed target values in the low frequencies, the trend was toward over-amplification.

Correlation coefficients were calculated for this subset of data. The results showed that the correlations were not higher than those measured for the entire subject group. Since thresholds of $130 \mathrm{~dB}$ HL were used to determine prescribed gain for subjects who demonstrated no measurable thresholds, the possibility for skewed data existed. However, even when that data was excluded from the calculation, the 
Table 7

Means, Standard Deviations, and Correlation Coefficients for Ears with Measurable

Hearing at all Test Frequencies

\begin{tabular}{|c|c|c|c|c|c|c|}
\hline \multirow{2}{*}{\multicolumn{2}{|c|}{ Frequency $(\mathrm{Hz})$}} & \multicolumn{2}{|c|}{$P x$} & \multicolumn{2}{|c|}{ Actual } & \multirow[t]{2}{*}{$r$} \\
\hline & & Mean & St. Dev & Mean & St. Dev. & \\
\hline 250 & $(n=20)$ & 44 & 8.03 & 44.75 & 6.61 & 0.10 \\
\hline 500 & $(n=20)$ & 48 & 6.35 & 51.20 & 7.23 & 0.06 \\
\hline 1000 & $(n=19)$ & 58.17 & 4.26 & 59.28 & 9.22 & 0.22 \\
\hline 2000 & $(n=13)$ & 66.46 & 2.71 & 59.15 & 6.17 & 0.06 \\
\hline 4000 & $(n=11)$ & 66.36 & 5.16 & 53.91 & 7.97 & -0.12 \\
\hline
\end{tabular}

Note. $P x=$ Prescribed 2 cc. coupler gain in dB SPL.

$n=$ Number of ears.

Subjects who did not exhibit measurable thresholds were eliminated from the calculation at each frequency. Therefore, $\mathrm{n}$ differs as a function of frequency. 
correlations are still very low.

\section{$\underline{\text { Conclusion }}$}

The results of this research indicated that the amplification characteristics of 16 children with profound hearing impairments differed significantly from those that were prescribed for the subjects using the DSL selection method. When compared to the DSL targets, the majority of the subjects received over-amplification in the low frequencies which has been shown to produce an upward spread of masking which may interfere with consonant perception. Additionally, over-amplification of the speech signal can result in saturation of the hearing aid and distortion of the speech signal. The majority of the subjects were also under-amplified in the high frequencies when compared to the DSL targets which could result in phonemic and morphemic perception errors.

It is critical that children who are learning speech and language receive an accurate and consistent representation of the speech signal. Prescriptive procedures other than the DSL have limitations when applied to children. They are based on the needs of adults who have an intact speech and language system and can function with some decrease in the audibility of the speech spectrum. Additionally, many prescriptive methods, such as the Cox (1983), and Pascoe (1978) procedures, require subjective sound comfort and loudness judgements that young children cannot make.

The DSL method also has limitations, but at this time it is the only prescriptive method that exists which is an objective measure of both amplification requirements and hearing aid assessment. Additionally, it is the only method which is designed for 
use with children. The present study has shown the difficulty of achieving prescribed gain targets for children who have profound hearing losses.

\section{Study Limitations}

There are a number of limitations to the present study. First, electroacoustic analysis was used to measure the frequency characteristics of the subject's amplification systems. When using this method, correction factors are applied to the measurement to account for the difference in SPL developed in the $2 \mathrm{cc}$. coupler and the SPL developed in the human ear canal. The differences are due to the differences in volume, impedance, and resonance characteristics of the human ear canal versus the $2 \mathrm{cc}$. coupler. The correction factors rely on averaged data of ear canal volume estimates and may not have been representative of the ear canals of the individual subjects. The DSL approach advocates using real-ear measurements to evaluate hearing aid fittings for children (Seewald et al. 1987). It is possible that the data would show differences, had it been evaluated using real-ear measures.

Another limitation of this study concerns the small subject pool. Ideally, a larger group of subjects will be used in future research. Additionally, all of the subjects that participated in this study were fit with their amplification systems at the same facility. Therefore, the results gathered from this data cannot be generalized to the hearing aid fittings of all profoundly hearing-impaired children.

\section{Clinical Implications}

The primary implication of this study concerns selecting appropriate gain for children who have profound hearing impairments. It is crucial that children receive 
the maximum benefit from their amplification systems. Appropriate amplification of a child's residual hearing may make the difference in the child's social, academic, and speech and language development. Adult selection strategies may not be appropriate for children. Audiologists should strive to achieve the goals prescribed by the DSL.

Over-amplification of low frequency energy may be easily modified, thus audiologists should strive to attain the DSL prescribed gain targets in the low frequencies. Prescribed gain targets in the high frequencies may not be achieved for children who have profound hearing losses. When deviations from the prescribed gain cannot be modified, it will be necessary for audiologists to make clinical judgements about acceptable compromises.

However, even when the prescribed goals can be realized, it is important to remember that the quality of the signal perceived is still unknown. No prescriptive method can indicate whether the individual child can discriminate or use the amplified sound in a meaningful way.

Sensorineural hearing losses affect not only the intensity of the signal, but also the perceived quality. Distortion of sound quality can interfere with the perception of time onset and offset of sounds, as well as the ability to separate the frequency components of the signal (Skinner, 1988). The degree of hearing loss is not the sole determining factor in the individuals capability to discriminate the different sounds of speech. Therefore, an audible speech signal alone is not sufficient to ensure speech perception. It is, however, a prerequisite for speech perception. 


\section{Implications for Future Research}

Different severities of hearing loss, as well as different populations of subjects could be analyzed in future research to determine if differences in results between prescribed and measured gain exist in other subject groups. Additionally, it would be interesting to determine the achievability of reaching DSL targets in the high frequencies in subject groups with mild, moderate, and severe hearing losses.

Another implication for future research concerns the analysis of the maximum power output of the amplification systems of children who are profoundly hearing impaired.

Seewald and Ross (1988) stated that the setting of the maximum output was the most important aspect in the hearing aid fittings for young children. The DSL program generates target SSPL values as a function of frequency based on a linear function of the relationship between amplified speech and maximum real-ear SSPL.

It is possible that saturation and distortion of the acoustic signal may occur with over-amplification of low frequency speech energy. Additionally, it is possible that loudness discomfort levels could be exceeded by over-amplified speech energy. Children with profound hearing losses commonly have a reduced dynamic range between the threshold of audibility and the threshold of discomfort.

Finally, a longitudinal study that would monitor the progress and changes in the selection of amplification characteristics for children, from the first selection of the hearing aid until reliable threshold data could be obtained, would provide some insight into how accurate the DSL prescription method is in initially predicting the SSPL. 


\section{Summary}

The present study examined the achievability of realizing DSL prescribed gain targets for children who have profound hearing losses. The amplification systems of 16 children were examined to determine how the gain they were receiving, as a function of frequency, compared with the gain that would be prescribed for their hearing losses by the DSL method. Prescribed $2 \mathrm{cc}$. coupler gain was calculated as a function of frequency for each subject based on the child's hearing thresholds at 250 , $500,1000,2000$, and $4000 \mathrm{~Hz}$. The 20 amplification systems worn by the subjects were electroacoustically analyzed at their use settings with an input of $60 \mathrm{~dB}$ SPL. The prescribed $2 \mathrm{cc}$. coupler gain was then compared with the measured $2 \mathrm{cc}$. coupler gain. An acceptance criteria of + or $-5 \mathrm{~dB}$ SPL was used to determine significant differences between measured versus prescribed gain. The data was described and analyzed to determine if a predictable relationship existed between the two sets of data.

The results indicated that none of the subjects satisfied the prescribed criteria at all frequencies. In the low frequencies of 250,500 , and $1000 \mathrm{~Hz}$, the majority of subjects were over-amplified when compared to the prescribed gain. In the high frequencies of 2000 and $4000 \mathrm{~Hz}$, the majority of the subjects received insufficient gain according to the prescribed amplification targets. Correlation coefficients suggested very weak relationships between the prescribed and measured gain at each test frequency.

Future research is suggested to investigate other aspects of hearing aid fittings for children with profound hearing losses such as distortion and saturation due to over- 
amplified low frequency speech energy. Additionally, other subject groups could be analyzed to determine the feasibility of achieving prescribed DSL targets in children who have less severe hearing losses. 


\section{References}

American National Standards Institute. (1989) American national standard specification for audiometers. ANSI S3.6-1989. New York: American National Standards Institute.

Bader, J.L. (1982). Development of auditory skills in children who are hearing-impaired. In R.H. Hull (Ed.) Aural rehabilitation (pp. 88-94). San Diego, CA: Singular Publishing Group.

Berger, K., Hagberg, E., \& Rane, R. (1984). Prescription of hearing aids. (4th ed.) Kent, OH: Herald Press House.

Boothroyd, A. (1982). Hearing impairments in young children. Englewood Cliffs, NJ: Prentice Hall.

Byrne, D. \& Dillon, H. (1986) The National Acoustic Laboratories new procedure for selecting the gain and frequency response of a hearing aid. Ear and Hearing, 7 , $257-265$.

Chomsky, N. (1966). Aspects of the theory of syntax. Cambridge, Mass: MIT Press.

Clopton, B., \& Silverman, M. (1977). Plasticity of binaural interaction II: Critical period and changes in midline response. Journal of Neurophysiology, 40, 12751280.

Cox, R.M. (1983). Using ULCL measures to find frequency/gain and SSPL 90. Hearing Instruments, $\underline{34}, 17-21,39$.

Cox, R.M. \& Alexander, G.C. (1990). Evaluation of in-situ output probe-microphone method for hearing aid fitting verification. Ear and Hearing, 11, 31-39.

Cox, R.M. \& Moore, J. (1988). Composite speech spectrum for hearing aid gain 
prescriptions. Journal of Speech and Hearing Research, $\underline{31}$, 102-107.

Danaher, E.M., Osberger, M.J., \& Pickett, J.M. (1973). Discrimination of formant frequency transitions in synthetic vowels. Journal of Speech and Hearing Research, 16, 439-451.

Davis, J.W., \& Mueller, H.G. (1987). Hearing aid selection. In H.G. Mueller \& V.C. Geoffrey (Eds.) Communication disorders in aging: Assessment and management. (pp. 408- 436). Washington DC: Galludet University Press.

DeCasper, A.J. \& Fifer, W.P. (1980). Of human bonding: newborns prefer their mother's voices. Science, $\underline{208}, 1174-1176$.

Dempsey, J.J. (1994). Hearing aid fitting and evaluation. In J. Katz (Ed.) Handbook of clinical audiology (pp. 723-735). Baltimore: Williams \& Wilkins.

Drylund, O. \& Lundh, P. (1990). Gain and feedback problems when fitting behind-theear hearing aids to profoundly hearing-impaired children. Scandinavian Audiology, 19, 89-95.

Easterbrooks, S.R. (1987). Speech/language assessment and intervention with school-age hearing-impaired children. In J. Alpiner \& P. McCarthy (Eds.) Rehabilitative audiology: Children and adults. (pp. 188-240). Baltimore: Williams and Wilkins.

Elfenbein, J.L., Hardin-Jones, M.A., \& Davis, J.M. (1994). Oral communication skills of children who are hard of hearing. Journal of Speech and Hearing Research, $\underline{37}$, 216- 226.

Engen, E. \& Engen, T. (1983). Rhode Island test of languagestructure manual. 
Baltimore: University Park Press.

Erber, N.P. (1973). Body baffle and real-ear effects in the selection of hearing aids for deaf children. Journal of Speech and Hearing Disorders, $\underline{38}, 224-231$.

Erber, N.P. \& Witt, L.H. (1977). Effects of stimulus intensity of speech perception by deaf children. Journal of speech and Hearing Disorders, 42, 271-277.

Evans, W., Webster, D., \& Cullen, J. (1983). Auditory brainstem responses in neonatally sound deprived CBA/J mice. Hearing Research, 10, 269-267.

Fikret-Pasa, S., \& Revit, L.J. (1992). Individualized correction factors in the preselection of hearing aids. Journal of Speech and Hearing Research, $\underline{35}, 384-400$.

Fry, D.B. (1978). The role and primacy of the auditory channel in speech and language development. In M. Ross \& T. Giolas (Eds.) Auditory management of hearing-impaired children. (pp. 15-43). Baltimore: University Park Press.

Green, R. (1988). Hearing aid selection and evaluation for preschool children. In B. McCormick (Ed.) Pediatric audiology: 0-5 years. (pp. 303-323). New Jersey: Whurr Publishers Ltd.

Hall, J.W. (1992). Handbook of auditory evoked responses. (pp. 304-360). Boston: Allyn \& Bacon.

Hawkins, D.B. (1983). Acoustical methods for selecting hearing aids. In G. Studebaker \& I. Hochberg (Eds.) Acoustical factors affecting hearing aid performance. (pp. 89102). Boston: Allyn \& Bacon.

Hawkins, D.B., Montgomery, A., Prosek, R., \& Walden, B. (1987). Examination of 2 issues concerning functional gain measurements. Journal of Speech and Hearing 
Disorders, 52, 56-63.

Hawkins, D.B., Morrison, T., Halligan, P., \& Cooper, W. (1989). Use of probe-tube microphone measurements in hearing aid selection for children: Some initial clinical experiences. Ear and Hearing, 10, 281-287.

Hogson, W.R. (1982). Considerations and strategies for children who are hearingimpaired. In R.H. Hull (Ed.) Aural rehabilitation (2nd ed.) (pp. 74-87). San Diego, CA: Singular Publishing Group.

Humes, L.E. (1982). Spectral and temporal resolution by the hearing-impaired. In G.A. Studebaker \& F.H.Bess (Eds.) The Vanderbilt hearing aid report. (pp. 16-31). Upper Darby, PA: Monographs in Contemporary Audiology.

Humes, L.E. (1986). An evaluation of several rationales for selecting hearing aid gain. Journal of Speech and Hearing Disorders, $\underline{51}, 272-281$.

James, S.L. (1990) Normal language acquisition. Austin, TX: Pro-Ed.

Jirsa, R.E., \& Norris, T.W. (1978). Relationship of acoustic gain to aided threshold improvement in children. Journalof Speech and Hearing Disorders, $\underline{43}$, 348-352. Levitt, H. (1978). The acoustics of speech production. In R. Giolas (Ed.) Auditory management of hearing-impaired children. (pp. 45-115) Baltimore: University Park Press.

Libby, E. (1985). State-of-the-art hearing aid selection procedures. Hearing Instruments. $\underline{36}$ (1), 30-38, 62 .

Ling, D. (1989). The foundations of spoken language forhearing-impaired children. 
Washington DC: Alexander Graham Bell Association for the Deaf.

Ling, D. (1994). Lecture notes. Presented at Lewis and Clark College, Portland, OR. Available from the A.G. Bell Association.

Lundh, P. (1982). Acoustical feedback problems associated with hearing aids. Oticon Research Unit; report no. 19-8-6.

Macrae, J. (1982). Invalid aided thresholds. Hearing Instruments, $\underline{33}$, 20-22.

Matkin, N.D. (1984). Wearable amplification: A litany of persisting problems. In J. Jerger (Ed.) Pediatric audiology: Current trends. (pp. 125-145). San Diego, CA: College Hill Press.

Matkin, N.D. (1987). Hearing instruments for children; Premises for selecting and fitting. Hearing Instruments, $\underline{38},(9), 14-16$.

McCandless, G.A., \& Lyregaard, P. (1983). Prescription of gain/output (POGO) for hearing aids. Hearing Instruments, $\underline{34}, 16-21$.

Millin, J. (1988a). Conventional hearing aid selection. In M. Pollack (Ed.)

Amplification for the hearing-impaired. (pp. 272-290). Orlando, FL: Grune and Stratton.

Millin, J. (1988b). Practical and philosophical considerations. In M. Pollack (Ed.) Amplification for the hearing-impaired. (pp. 145-174). Orlando, FL: Grune and Stratton.

Morris, T. (1977). An approach to calculating gain requirements for severely deaf children as a function of hearing loss which is independent of frequency response. Scandinavian Audiology, $\underline{6}, 21-26$. 
Northern, J.L., \& Downs, M.P. (1984). Hearing in children. (pp. 93-114, 271-295). Baltimore: Williams and Wilkins.

Northern, J.L., Grabbard, S.A., \& Kinder, D.L. (1990). Pediatric considerations in selecting and fitting hearing aids. In R. Sandlin (Ed.) Handbook of hearing aid amplification Vol. 2: Considerations and fitting practices. (pp. 113-132). Boston: College Hill Press.

Pascoe, D.P. (1978). An approach to hearing aid selection. Hearing Instruments, $\underline{29}$ (6), 12-16, 36.

Paul, P.V. \& Jackson, D.W. (1993). Toward a psychology of deafness: Theoretical and empirical perspectives. (pp. 32-41). Boston: Allyn and Bacon.

Ross, M. \& Seewald, R.C. (1988). Hearing aid selection and evaluation with young children. In F.H. Bess (Ed.) Hearing impairment in children. (pp. 190-213). Parkton, MD: York Press.

Schwartz, D., \& Larson, V. (1977). A comparison of three hearing aid evaluation procedures for young children. Archives of Otolaryngology, 103, 401-406.

Seewald, R.C. (1988). The desired sensation level approach for children: Selection and verification. Hearing Instruments, 18-20.

Seewald, R.C., Hudson, S.P., Gagne, J-P, \& Zelisko, D.L. (1992). Comparison of 2 methods for estimating the sensation level of amplified speech. Ear and Hearing, $\underline{13}, 142-149$.

Seewald, R.C. \& Ross, M. (1988). Amplification for young hearing-impaired children. In M. Pollack (Ed.) Amplification for the hearing-impaired. (pp. 213-267). New 
York: Grunne \& Stratton.

Seewald, R.C., Ross, M., \& Spiro, M.K. (1985). Selecting amplification characteristics for young hearing-impaired children. Ear and Hearing, $\underline{6}, 48-53$.

Seewald, R., Ross, M., \& Stelmachowicz, P. (1987). Selecting and verifying hearing aid performance characteristics for young children. Journal of the Academy of Rehabilitative Audiology, 20, 25-37.

Silverman, M. \& Clopton, B. (1977). Plasticity of binaural interaction I: Effect of early auditory deprivation. Journal of Neurophysiology, 40, 1266-1274.

Skinner, M.W. (1988). Hearing aid evaluation. New Jersey: Prentice Hall.

Skinner, M.W., Pascoe, D.P., Miller, J.D., \& Popelka, G.R. (1982). Measurements to determine the optimal placement of speech energy within the listener's auditory area: A basis for selection amplification characteristics. In G.A. Studebaker \& F.H. Bess (Eds) The Vanderbilt hearing- aid report. (pp. 161-169) Upper Darby, PA: Monographs in Contemporary Audiology.

Smith, C.R. (1975). Residual hearing and speech production in deaf children. Journal of Speech and Hearing Research, 18 , 795-811.

Stelmachowicz, P.G., Mace, A.L., Kopun, J.G., \& Carney, E. (1993). Long-term and short-term characteristics of speech: Implications for hearing aid selection for young children. Journal of Speech and Hearing Research, 36, 609-620.

Tess, R. (1967). Effects on early auditory restriction in the rat on adult pattern discrimination. Journal of Comparative Physiological Psychology, 63, 389-393.

Turner, C.W. \& Holte, L.A. (1985). Evaluation of FM amplification systems. Hearing 
Instruments, $\underline{36}, 7-12,56$.

Webster, D.B. \& Webster, M. (1977). Neonatal sound deprivation affects brainstem auditory nuclei. Archives of Otolaryngology, 103, 392-396.

Webster, D.B. \& Webster, M. (1979). Mouse brainstem auditory nuclei development. Annals of Otology, Rhinology, and Laryngology, 89, 684-688. 